\title{
Detection and identification of gonococcal L-Forms using a direct immunofluorescence test
}

\author{
SHEENA A. WAITKINS ${ }^{\star}+$ AND I. GEARY ${ }^{\star}$ \\ From the Neisseria Department ${ }^{\star}$, Statens Seruminstitut, Copenhagen, Denmark, \\ Department of Medical Microbiology, ${ }^{\star \star}$ University of Sheffield Medical School, Sheffield, and \\ Central Public Health Laboratory, + London
}

SUMMARY A fluorescent antibody test was used to identify L-Forms of $N$. gonorrhoeae induced in vitro. It was possible to differentiate the Large Bodies of the L-Forms from parent gonococci and the fluorescent reaction remained specific in the presence of tissue culture cells. A possible method to identify L-Forms of gonococci from patients presenting with postgonococcal urethritis is described.

\section{Introduction}

In the last few years there has been considerable interest in the L-Forms of Neisseria gonorrhoeae. Their presence in the genital secretions of patients who attended with suspected gonorrhoea was demonstrated by Gnarpe et al. (1972) and by Gnarpe and Wallin (1973). Although these authors isolated L-Forms from patients who were infected with $N$. gonorrhoeae, it is difficult to determine whether these L-Forms were present in the patient, or had been accidentally induced by the cultural techniques. The causative agents in postgonococcal urethritis are still unknown, but the presence of gonocococcal L-Forms was suggested by Holmes et al. (1967a) and in another study the same group (Holmes et al., $1967 \mathrm{~b}$ ) proposed that inadequate penicillin treatment might transform the gonococcus to its L-Form. These views have been partially substantiated by the findings of Barile et al. (1959) who demonstrated that of seven strains of penicillin-resistant $N$. gonorrhoeae, one strain transformed very easily to a penicillin-resistant gonococcal L-Form. L-Forms may also be responsible for clinical complicationssuch as gonococcal arthritis. Holmes et al. (1971) reported a case in which gonococcal L-Forms grew from 'sterile' synovial fluid, but their findings were not substantiated by clinical evidence.

There is no longer any doubt that the gonococcal L-Form can occur under in vitro conditions. Lawson

Address for reprints: S. A. Waitkins, Cross-Infection Reference Laboratory, Central Public Health Laboratory, Colindale Avenue, London NW9 SHT

Received for publication 30 November 1976 and Douglas (1973) gave an account of the induction and reversion of the L-Form of $N$. gonorrhoeae on cultural media but the presence of these same organisms in clinical specimens still has to be proved. This lack of proof is mainly due to inability to isolate and identify specifically the gonococcal L-Form without undertaking long and tedious laboratory techniques.

The results presented in this paper show an easy, effective, and specific method of identifying gonococcal L-Forms. Dienes (1942, 1966) described a simple staining method to illustrate the various elementary structures of bacterial L-Forms. He showed that all L-Forms consisted of both vacuolated Large Bodies (Fig. 1), and small granules growing from and/or around them. These observations have been substantiated by many workers, and it is now possible to say that in every case where bacterial L-Forms are developing, these distinct structures of the Large Body can be seen (Dienes, 1942; Weibull, 1963; Fass and Prior, 1974). In the current work, Large Bodies of developing gonococcal L-Forms were shown to be stained specifically with fluorescein-isothiocyanate (FITC) labelled rabbit antigonococcal globulin. The combination of the distinct structure and the specific fluorescent staining was used to identify the developing gonococcal L-Form, from in vitro induced L-Forms.

\section{Materials and methods}

MEDIA

Basic Growth Medium Difco GC medium base plus $2 \%$ defined supplement (White and Kellogg, 1965) was used. 


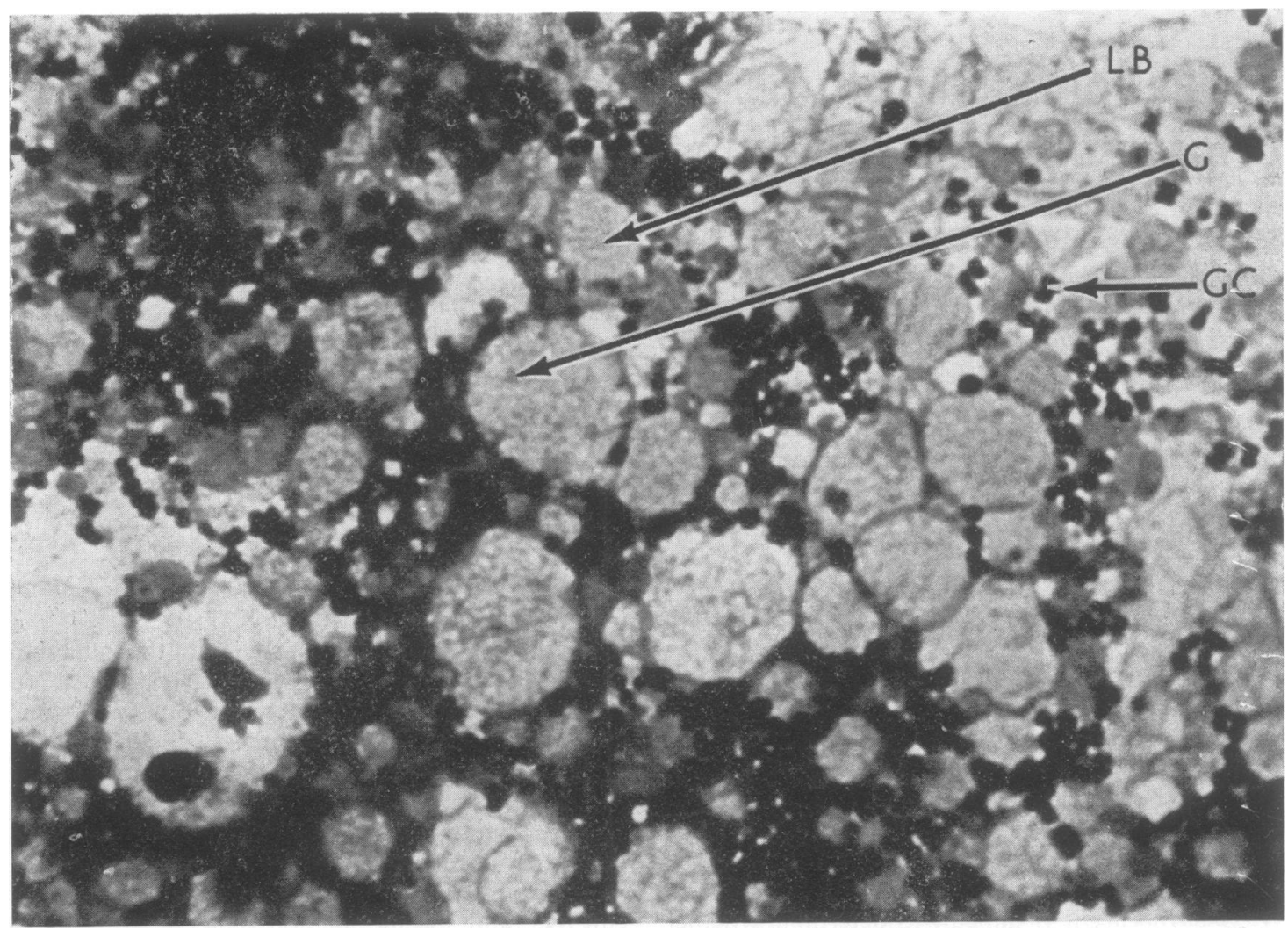

Fig. 1 Usual arrangement of structures found in mature L-Form colonies, $L$-Form at all stages can be seen: Large Bodies $(L B)$ interspersed with gonococci $(G C)$, granules $(G)$ can also be seen inside the Large Body. Dienes' stain $\times 1000$.

Induction Medium was prepared using the Basic Growth Medium described above and adding $10 \%$ inactivated horse serum, 500 units $/ \mathrm{ml}$ benzylpenicillin, and $1 \%$ polyvinylpyrrolidone (PVP) with a molecular weight of 700000 (BDH Chemicals Ltd). The Basic Growth Medium plus $1 \%$ PVP was autoclaved at a temperature of $121^{\circ} \mathrm{C}$ for $15 \mathrm{~min}$; when it had cooled to $55^{\circ} \mathrm{C}$ the penicillin, horse serum, and defined supplement were added.

Reversion Medium was prepared using the Basic Growth Medium with $10 \%$ inactivated horse serum and $10 \%$ sucrose solution as an osmotic stabiliser.

Five per cent lysed blood agar was prepared by using Columbia agar (Oxoid) $39 \mathrm{~g}$ and distilled water $1000 \mathrm{ml}$. The agar was soaked for $15 \mathrm{~min}$, mixed, and autoclaved at a temperature of $121^{\circ} \mathrm{C}$ for $15 \mathrm{~min}$. When it had cooled to $55^{\circ} \mathrm{C}, 50 \mathrm{ml}$ of sterile blood (Wellcome), lysed by repeated freezing and thawing, was added.

\section{ORGANISMS}

Organisms from Sheffield and Copenhagen were examined. All strains of $N$. gonorrhoeae from Sheffield were isolated on $5 \%$ lysed horse blood agar containing $1 \%$ vancomycin (500 units $/ \mathrm{ml})$. They were identified by colonial form, Gram stain, a positive oxidase reaction, and the fermentation of glucose but not of maltose or sucrose. Fermentation reactions were carried out using a modified carbohydrate medium containing Difco GC medium base with $1 \%$ sugar concentrations (Flynn and Waitkins, 1972).

Isolation and identification of the Danish strains were performed by the methods recommended by Reyn (1969).

After only one subculture Kellogg types 1, 2, 3, and 4 colonies were identified and grown on Basic Growth Medium for 18 hours at a temperature of $37^{\circ} \mathrm{C}$ in $5 \% \mathrm{CO}_{2}$ atmosphere. The organisms were 
harvested by scraping off, suspending, and diluting in saline to a final concentration of $10^{8}$ gonococci $/ \mathrm{ml}$ as described by Miles et al. (1938). This suspension was used in the test systems.

\section{INDUCTION OF GONOCOCCAL L-FORMS}

L-Forms of gonococci were induced by flooding $0.1 \mathrm{ml}$ of the gonococcal suspension on to freshly poured plates of Induction Medium. A control for gonococcal viability was included by culturing on Basic Growth Medium. The inoculated plates were then incubated at $36^{\circ}$ in a moist atmosphere containing $10 \% \mathrm{CO}_{2}$ and $90 \%$ humidity. The surface of the plates was inspected every day for possible L-Form colony development using a stereoscan plate microscope.

\section{IDENTIFICATION OF L-FORMS}

As already described, the L-Forms consist of three distinct morphological structures: the Large Body, the elementary corpuscles, and granules. Because the Large Bodies are so distinct we propose to use their presence as an indication of L-formation while using the fluorescent antibody (FA) technique in the identification of the gonococcal L-Form.

\section{METHODS USED FOR IDENTIFICATION}

Block removal technique, using Dienes' stain (1942) (Fig. 2)

At intervals in the development of the L-Form, blocks of agar approximately $1 \mathrm{~cm}^{2}$ were removed

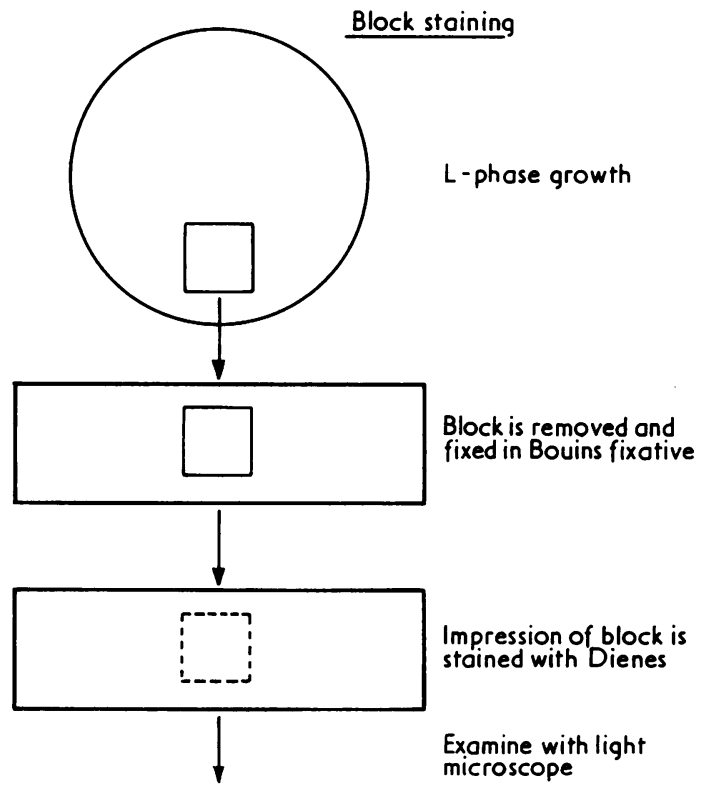

Fig. 2 Block staining. using a sterile scalpel blade. The block was placed growth downwards on a cleaned microscope slide and fixed in situ with Bouin's fixative overnight in a moist box at $37^{\circ} \mathrm{C}$. After fixation the blocks were removed and discarded, the slides were washed with distilled water to remove excess stain, and treated with $70 \%$ alcohol for 1 hour. After 1 hour the slides were washed again in water and finally stained using Dienes' stain for 1 hour.

\section{Fluorescent antibody technique (Fig. 3)}

The technique for fluorescence staining was initially very like that of Dienes' staining; agar blocks were cut out as above and pressed on to slides as before. The imprint that remained was then processed for the FA method.

The imprinted slide was fixed with methanol for $5 \mathrm{~min}$, washed in water for 10 seconds, dried and stained with FITC-labelled rabbit gonococcal globulin for at least $30 \mathrm{~min}$ in a moist box at room temperature. After the specimen had been stained, excess conjugate was washed off for $10 \mathrm{~min}$, then allowed to dry and finally mounted in glycerol under a cover slip.

Antigonococcal conjugate was prepared by the Lind method (Lind, 1967, 1975) and used at $1: 16$ dilution. This was made using $0.1 \mathrm{ml}$ of diluted conjugate, $0.2 \mathrm{ml}$ antistaphylococcal serum, and $1.3 \mathrm{ml}$ distilled water.

Large Bodies were found to fluoresce very brightly using this method.

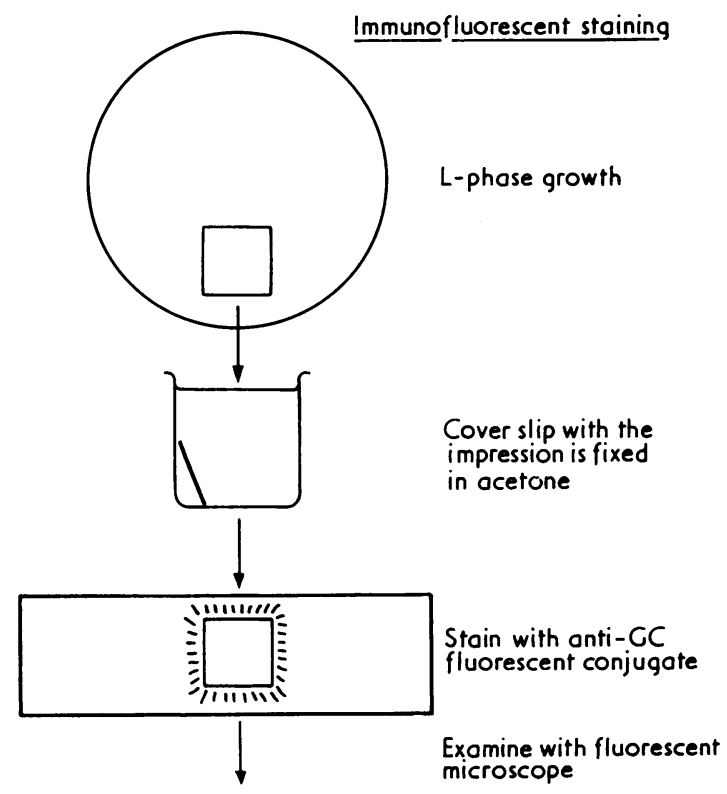

Fig. 3 Fluorescent antibody (FA) technique. 


\section{Reversion technique}

In the introduction it was explained that some L-Forms are unstable and can revert to their parental form. The L-Forms of $N$. gonorrhoeae are also capable of such reversions and this phenomenon can be used in the specific identification of gonococcal L-Forms. The L-Form is allowed to revert to the parent bacterial organism on suitable non-inducing medium, and in the case of gonococcus, the medium used is similar to the Induction Medium, except that it does not contain any antibiotics and has sucrose as an osmotic stabiliser. Once reversion to the parent gonococcus has occurred, the identification of the organisms is as usual.

\section{Method}

Agar blocks were cut out of the Induction Medium and placed growth side downwards on the Reversion Medium. The agar block was then gently pushed forwards and backwards over the entire surface of the new medium, followed by incubation at $36^{\circ} \mathrm{C}$ in a moist atmosphere containing $10 \% \mathrm{CO}_{2}$ and $90 \%$ humidity. When reversion occurred the resulting gonococcal colony was identified by Gram's stain, positive oxidase reaction, and sugar fermentation reactions.

\section{TISSUE CULTURE CELlS}

Media

Eagle's Minimum Essential Medium (MEM) was obtained as a 10 times concentrated stock solution from Wellcome Reagents Ltd (Eagle, 1959). Eagle's Growth Medium (EGM), $100 \mathrm{ml}$ of MEM, $100 \mathrm{ml}$ calf serum (Biocult), and $20 \mathrm{ml}$ of $4.4 \%$ sodium bicarbonate solution were added to $780 \mathrm{ml}$ deionised water.

Osmotically stabilised EGM (for L-Forms) was obtained as above for EGM plus $1 \%$ sterile PVP.

Tissue culture cells

Vero cells were grown on cover slips $(1 \times 4 \mathrm{~cm})$ inside Leighton tubes which were then incubated statically at $37^{\circ} \mathrm{C}$ at an angle of $5^{\circ}$ from the horizontal to ensure that a monolayer of cells would form on the cover slips. The final tissue culture cell concentration was approximately $1 \times 10^{8}$ cells per $\mathrm{ml}$.

\section{Organisms}

$N$. gonorrhoeae were prepared as before but the final suspension of organisms was made in EGM.

\section{Gonococcal L-Forms}

Mature L-Form colonies were scraped off and washed in osmotically stabilised EGM. The colonies were concentrated by centrifugation $\times 5000 \mathrm{rev} / \mathrm{min}$ for $5 \mathrm{~min}$, and the final concentration was adjusted to approximately $1 \times 10^{8}$ L-Forms per $\mathrm{ml}$ with the same medium.

\section{Method of infecting the cells}

Cells were infected with either gonococci or their L-Forms as described by Waitkins and Flynn (1973); $0.1 \mathrm{ml}$ of the suspension of organisms was added to each Leighton tube containing tissue culture cells, and then incubated at $37^{\circ} \mathrm{C}$ for six hours. After this time each cover slip was washed thoroughly in phosphate buffered saline (pH 7.2) to remove any adherent organisms and then stained by the FA method.

Fluorescent antibody technique for tissue culture cells The infected tissue culture cells were first fixed in cold acetone for $5 \mathrm{~min}$, and then washed in phosphate buffered saline (pH 7.2) to remove excess acetone. After the cover slips were dry they were stained with FITC-labelled rabbit gonococcal immunoglobulin G purified by diethylaminoethyl cellulose (DEAE)

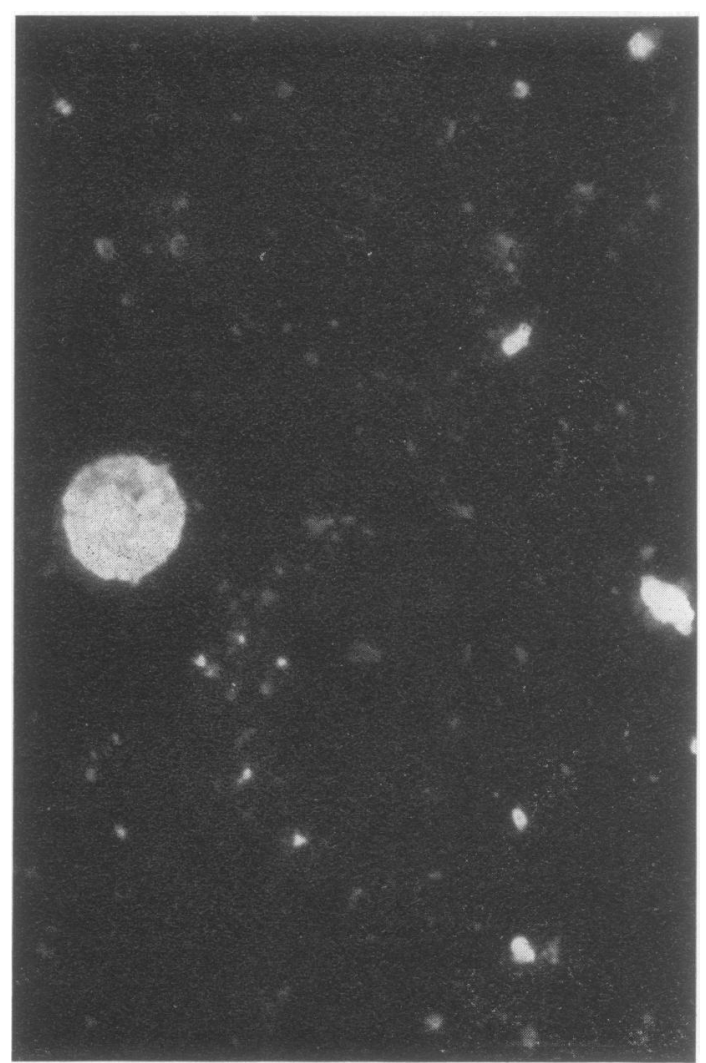

Fig. 4 Typical morphology of a Large Body when stained with FITC-labelled rabbit gonococcal immunoglobulin $\times 1000$. 
chromatography (optical density ratio 0.7 ) and used in a one-step inhibition test at a dilution of $1: 2$. The fluorescent staining technique was similar to the FA block staining method described above. The staining action took place in a moist box at room temperature for $30 \mathrm{~min}$ after which the cover slips were washed with water and allowed to dry in air before they were mounted in glycerol on clean microscope slides and viewed on a Zeiss standard microscope equipped for fluorescence microscopy.

\section{Reading of $F A$ staining results}

In both the block stains and the tissue culture cells the method for reading the results was the same. The degree of fluorescence was recorded in values from 0 to ++++ . The values +++ and ++++ corresponded to brilliant, apple-green fluorescence. The positive reaction was characterised by the typical morphology of the organisms, the Large Body of the L-Form (Fig. 4), and the diplococci of the gonococcus (Fig. 5), and by the degree of fluorescence $(+++$ and ++++$)$.

\section{Control organisms}

The L-Form of Staphylococcus aureus strain NCTC 8530 Cowan 1 and Mycoplasma hominis were grown on the same medium as the gonococcal L-Forms and acted as controls for the specificity of the FA method. These control organisms were subjected to the same FA block procedures as the gonococcal L-Forms.

\section{Results}

As Table 1 shows, 55 strains of $N$. gonorrhoeae were induced to form gonococcal L-Forms. These were examined for the production of Large Bodies using Dienes' staining method and when found to possess these structures they were further examined by the FA method for specific identification of the organisms. All Large Bodies derived from gonococci were found to have positive FA reactions similar to

Table 1 Number of strains of $\mathbf{N}$. gonorrhoeae examined for the production of L-Forms

\begin{tabular}{|c|c|c|c|}
\hline \multicolumn{4}{|c|}{ Number of strains } \\
\hline $\begin{array}{l}\text { Of } \mathrm{N} \text {. } \\
\text { gonorrhoeae }\end{array}$ & $\begin{array}{l}\text { Induced to } \\
\text { form L-Forms }\end{array}$ & $\begin{array}{l}\text { Giving a } \\
\text { positive } F A \\
\text { reaction }++ \\
\text { to }++++\end{array}$ & $\begin{array}{l}\text { Reverting to } \\
\text { their parental } \\
\text { types }\end{array}$ \\
\hline 55 & 55 & 55 & 40 \\
\hline
\end{tabular}

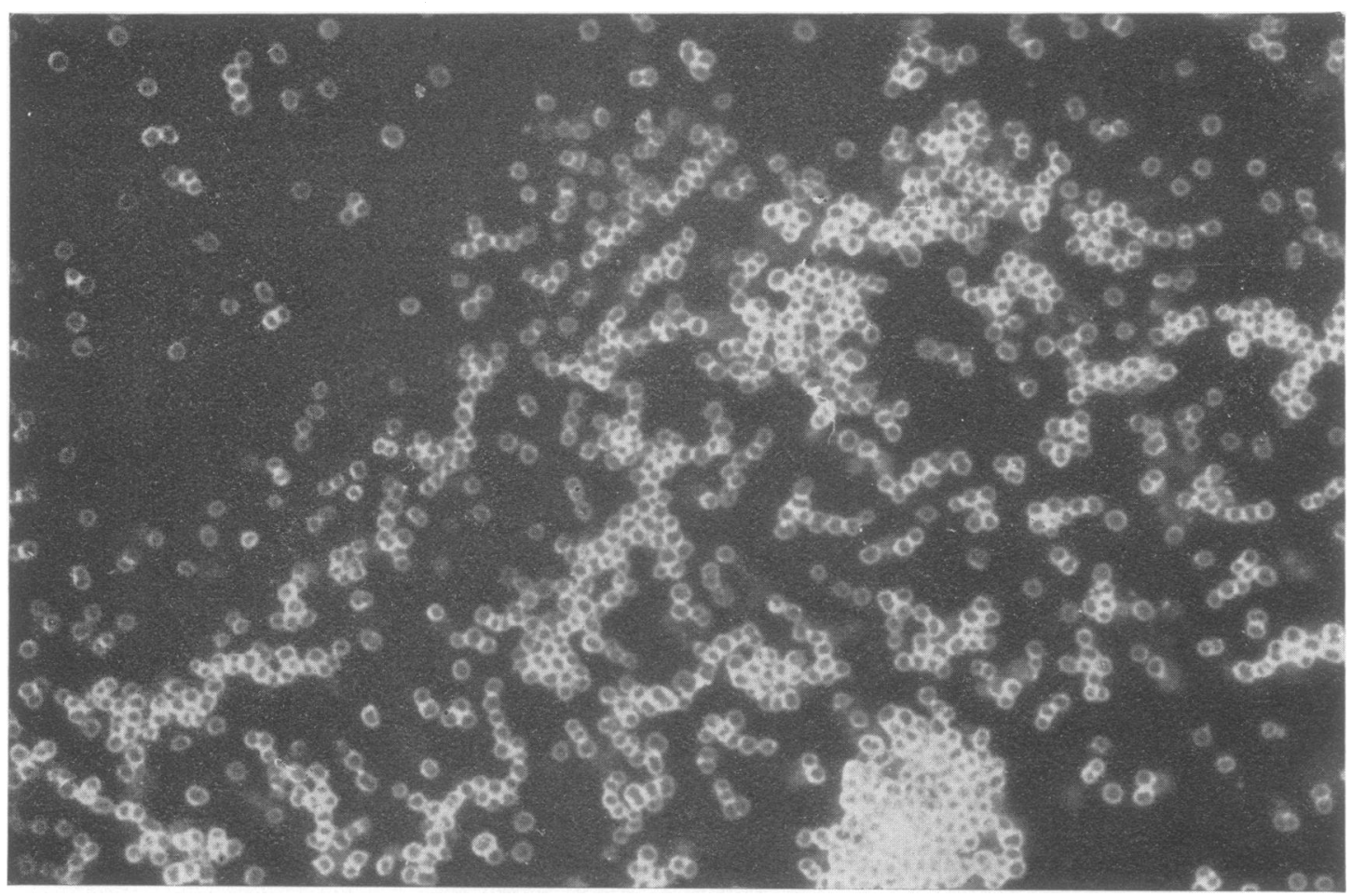

Fig. 5 Typical diplococcal gonococci stained with FITC-labelled rabbit gonococcal immunoglobulin $\times 1000$. 
their parent gonococci varying in values of between ++ to ++++ . Forty of the 55 strains reverted to the parent gonococcal strains and could subsequently be identified using classical bacteriological techniques. Furthermore, the gonococci reverted to their original Kellogg colonial types. Table 2 shows that this FA reaction was specific for L-Forms from gonococci only. The control L-Forms from $S$. aureus and $M$. hominis did not react with the antigonococcal conjugate.

Table 2 Fluorescent antibody method applied to control micro-organisms

\begin{tabular}{lll}
\hline Micro-organisms & Bacterial form & L-Form \\
\hline Staphylococcus aureus NCTC 8530 & 0 & 0 \\
Mycoplasma hominis & - & 0 \\
Neisseria gonorrhoeae & ++++ & ++++ \\
\hline
\end{tabular}

Figures 1, 6, and 7 show the distinct differences in the microscopical appearance of parent gonococci and their L-Forms. Figure 6 illustrates the classical arrangement of gonococci using Dienes' block staining technique, whereas Fig. 7 shows the one
Large Body isolated on its own showing the cytoplasmic content of this structure. Figure 1 illustrates more clearly the usual arrangement of structures found in the mature L-Form colonies, L-Form at all stages can be seen; Large Bodies were interspersed with gonococci and other L-phase structures in the process of L-Form production. It is clear from these figures that the potential L-Form colonies can be recognised by the presence of the Large Body, because in all cases when Large Bodies appear typical L-Form colonies as seen in Fig. 8, will eventually develop either in days or weeks.

The specific identification of these Large Bodies can be achieved using FA methods. Figure 5 illustrates the control gonococci giving a specific positive reaction characterised by the typical diplococcal morphology of the micro-organism and the degree of fluorescence of ++++ . The corresponding FA reaction of the gonococcal Large Bodies can be seen in Fig. 4, the same degree of specific reaction was characterised this time by the distinct morphological structure of the Large Body.

The FA technique was then used to identify gonococci and their L-Forms which had been

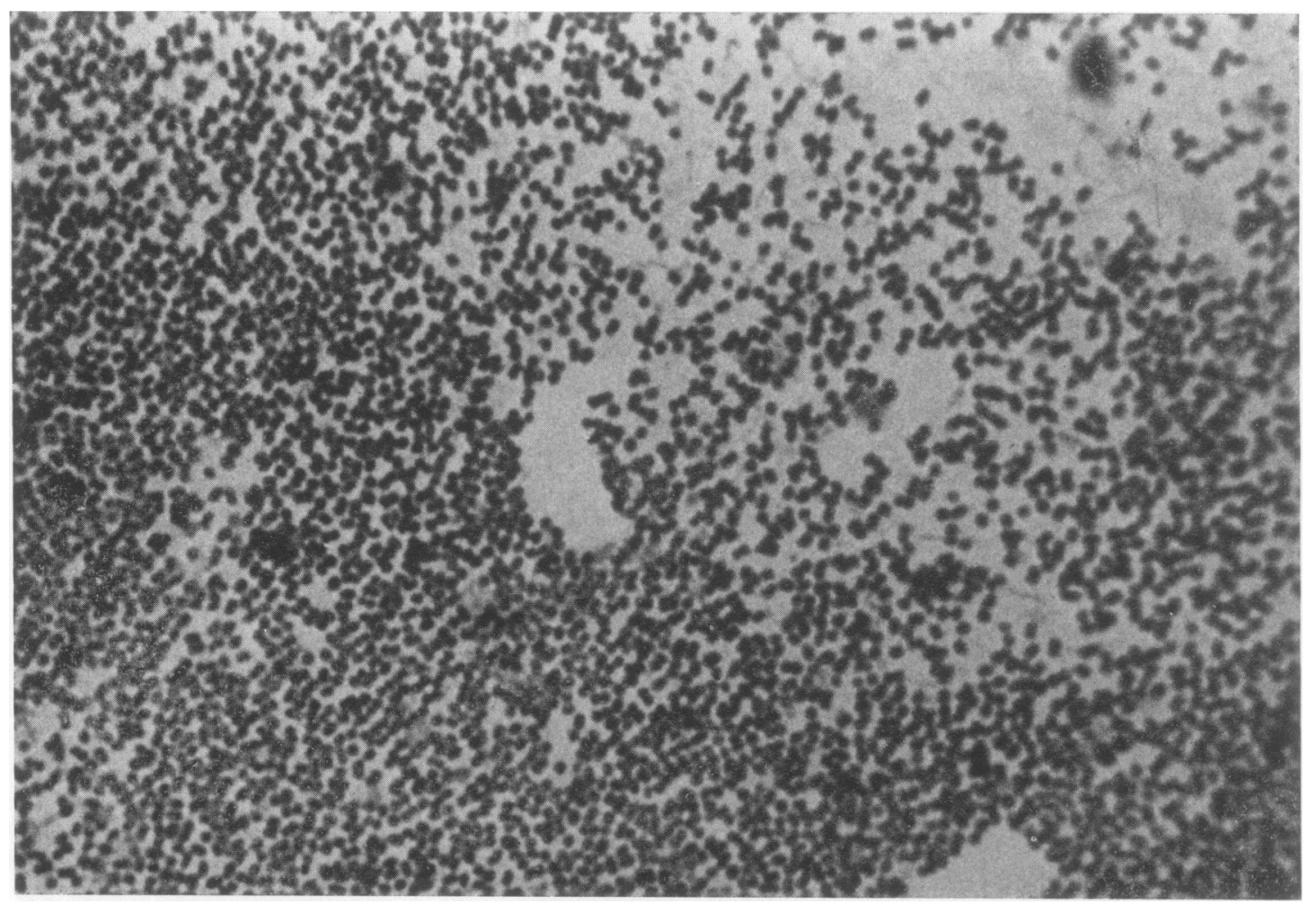

Fig. 6 Classical arrangement of gonococci using Dienes' block staining technique $\times 640$. 


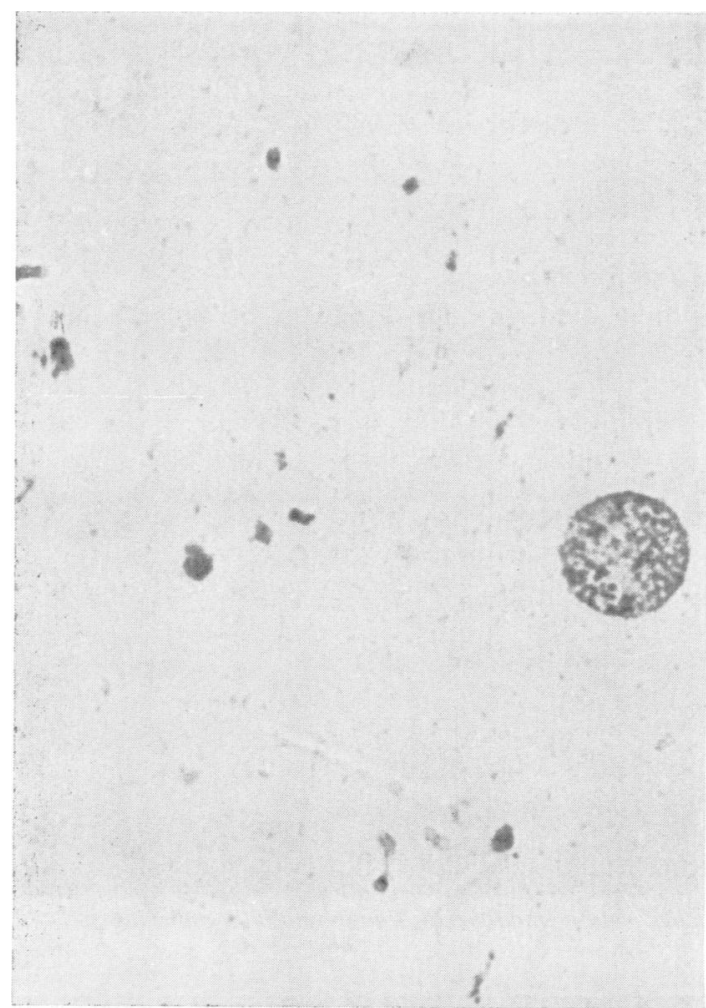

Fig. 7 An isolated Large Body on its own, showing its cytoplasmic content. Dienes' stain $\times 1000$.

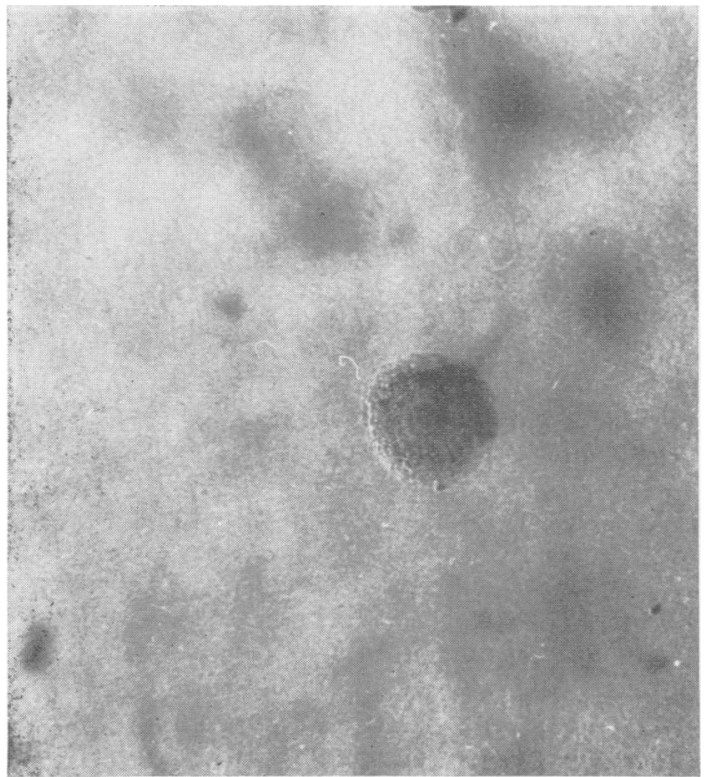

Fig. 8 Typical gonococcal L-Form colony after 12 days' growth $\times 24$ inoculated on to tissue culture cells. Vero cell sheets were prepared and inoculated with the organisms as described above; however, it was necessary to use the highly purified fluorescent conjugate because of gross non-specific fluorescence by the tissue culture cells. Using this purified conjugate the nonspecific reactions from the tissue cells were eliminated while the gonococcus and their L-Forms gave a strongly positive fluorescence.

Figures 9 and 10 illustrate the resulting fluorescent reactions. Figure 9 shows the control gonococcus adhering to the tissue culture cells and Fig. 10 demonstrates the Large Body adhering to the background culture cells.

\section{Discussion}

Observations on the morphology of gonococcal LForms induced in vitro showed the presence of Large Bodies in all the cultures. They were easily identified, and are considered characteristic in the morphology of the developing L-phase cultures. The Large Body may or may not be viable in its own right, but it is certainly morphologically distinct and appears regularly whenever gonococci are induced to the L-phase; because of this we believe that it can be used as an identification structure for the presence of L-Forms.

In all strains tested, the Large Bodies gave strongly positive fluorescent reactions and were easily distinguished from the granules and other elements of the L-phase cultures.

The FA test was then applied to a mixed culture of L-Forms and gonococci, and both the Large Bodies and gonococci produced bright fluorescence. However, it was possible to distinguish the Large Bodies of the L-Forms from the parent gonococci by the distinct morphological difference. Also there was a high level of specificity in the detection of gonococci and their L-Forms as neither the mycoplasmal nor the staphylococcal L-Form was stained by the antigonococcal conjugate.

Having ascertained that it was possible to use the FA technique to identify the L-phase $N$. gonorrhoeae, we then used a highly purified conjugate to demonstrate this specific fluorescent reaction in the presence of tissue culture cells.

The strong degree of fluorescence exhibited by gonococcal L-phase Large Bodies and the absence of fluorescence from the tissue culture cells lead us to believe that this test may have potential in identifying gonococcal L-Forms in specimens from patients presenting with suspected postgonococcal urethritis. 


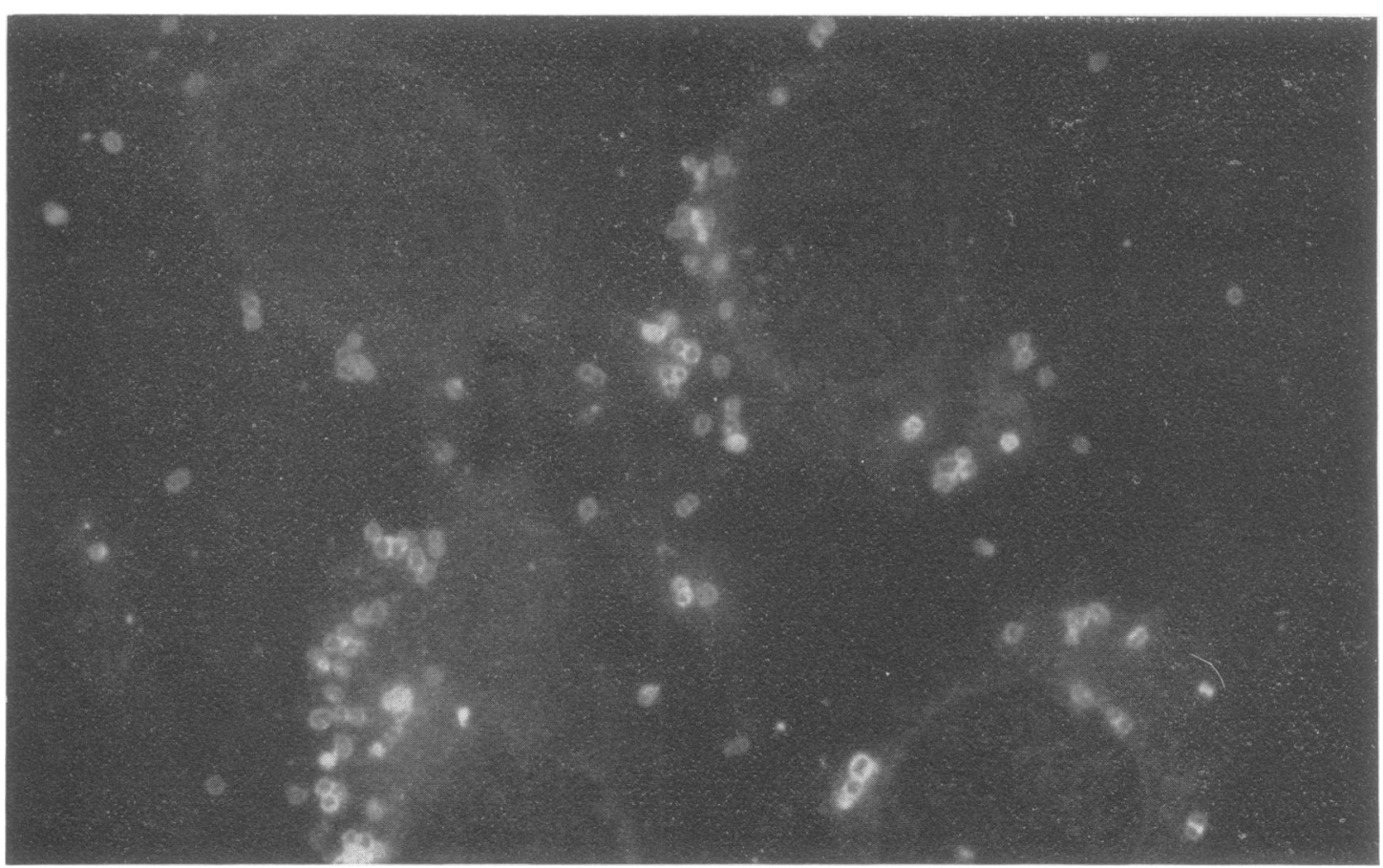

Fig. 9 Control gonococci which have been stained by FITC-labelled rabbit gonococcal immunoglobulin adhering to Vero tissue culture cells $\times 1000$. :

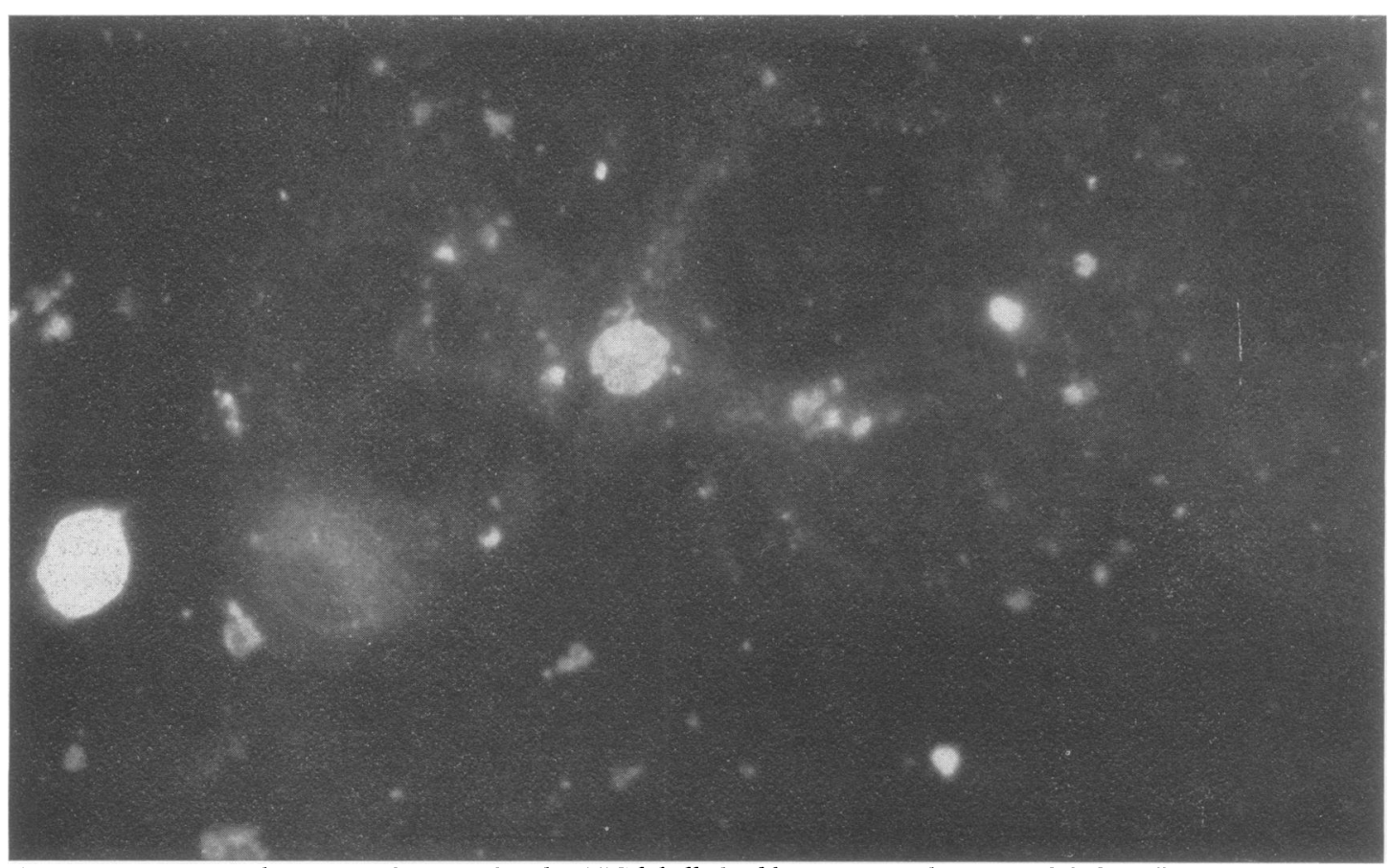

Fig. 10 A gonococcal Large Body stained with FITC-labelled rabbit gonococcal immunoglobulin adhering to Vero tissue culture cells $\times 1000$. 
We should like to thank the World Health Organisation for providing one of us (Sheena Waitkins) with a training grant to perform the work undertaken in Denmark, and also Dr Alice Reyn for useful comments on the preparation of this manuscript. The technical assistance of Fru Lene Berthelessen is gratefully acknowledged by Dr S. A. Waitkins.

\section{References}

Barile, M. F., Van Zee, G. K., and Yaguchi, R. (1959). The occurrence of failures in penicillin treated gonorrhoeal urethritis. I. The significance of L-form transformation of Neisseria gonorrhoeae to penicillin resistance. Antibiotic Medicine and Clinical Therapy, 6, $470-479$.

Dienes, L. (1942). Significance of large bodies and development of L-type colonies in bacterial cultures. Journal of Bacteriology, 44, 37-73.

Dienes, L. (1966). Permanent stained agar preparation of Mycoplasma and L-forms of bacteria. Journal of Bacteriology, 93, 689-692.

Eagle, H. (1959). Amino acid metabolism in mammalian cell cultures. Science, 130, 432-437.

Fass, R. J., and Prior, R. B. (1974). Light scanning, and transmission electron microscopy of stable staphylococcal L-forms. Annals of the New York Academy of Sciences, 236, 76-95.

Flynn, J., and Waitkins, S. A. (1972). A serum-free medium for testing fermentation reactions in Neisseria gonorrhoeae. Journal of Clinical Pathology, 25, 525-527.

Gnarpe, H., and Wallin, J. (1973). Studies in venereal disease. II. Improved diagnosis of gonorrhoea by the parallel use of conventional and L-phase media for culture. British Journal of Venereal Diseases, 49, 505-507.

Gnarpe, H., Wallin, J., and Forsgren, A. (1972). Studies in venereal disease. I. Isolation of L-phase organisms of $N$. gonorrhoeae from patients with gonorrhoea. British Journal of Venereal Diseases, 48, 496-499.

Holmes, K. K., Gutman, L. T., Belding, M. E., and Turck, M. (1971). Recovery of Neisseria gonorrhoeae from sterile synovial fluid in gonococcal arthritis. New England Journal of Medicine, 284, 318-320.

Holmes, K. K., Johnson, D. W., and Floyd, T. M. (1967a). Studies of venereal diseases. III. Double blind comparison of tetracycline hydrochloride, and placebo in treatment of non-gonococcal urethritis. Journal of the American Medical Association, 202, 138-140.

Holmes, K. K., Johnson, D. W., Floyd, T. M., and Kvale, P. A. (1967b). Studies of venereal diseases. II. Observations on the incidence, etiology and treatment of the postgonococcal urethritis syndrome. Journal of the American Medical Association, 202, $467-473$.

Lawson, J. W., and Douglas, J. T. (1973). Induction and reversion of the L-form of Neisseria gonorrhoeae. Canadian Journal of Microbiology, 19, 1145-1151.

Lind, I. (1967). Identification of Neisseria gonorrhoeae by means of fluorescent antibody technique. Acta pathologica et microbiologica Scandinavica, 70, 613-629.

Lind, I. (1975). Methodologic aspects of routine procedures for identification of Neisseria gonorrhoeae by immunofluorescence. Annals of the New York Academy of Sciences, 254, 400-406.

Miles, A. A., Misra, S. S., and Irwin, J. O. (1938). Estimation of bactericidal power of blood. Journal of Hygiene, 38, 732-749.

Reyn, A. (1969). Recent developments in laboratory diagnosis of gonococcal infections. Bulletin of the World Health Organisation, 40, 245-255.

Waitkins, S. A., and Flynn, J. (1973). Intracellular growth and type variation of Neisseria gonorrhoeae in tissue cell cultures. Journal of Medical Microbiology, 6, 399-403.

Weibull, C. (1963). Size of minimal reproductive units of bacterial L-forms. Proceedings of the Society for Experimental Biology and Medicine, 113, 32-34.

White, L. A., and Kellogg, D. J., Jr (1965). Neisseria gonorrhoeae identification in direct smears by a fluorescent antibody counterstain method. Applied Microbiology, 13, 171-174. 